\title{
ANALISE DA CADEIA PRODUTIVA DO LEITE NA BACIA LEITEIRA DO SERTÃO ALAGOANO NO PERÍODO DE 1990 A 2010¹
}

\author{
José Francisco Oliveira de Amorim \\ Professor da Faculdade de Economia, Administração e Contabilidade - FEAC/UFAL. \\ Maceió, AL, Brasil. \\ josefranciscoamorim@gmail.com \\ Cibele Cavalcante Gomes \\ Economista (Unidade Santana do Ipanema/Campus do Sertão - UFAL) \\ Santana do Ipanema, AL, Brasil. \\ cibeleanjos@live.com
}

\begin{abstract}
Andreia Rodrigues Ferreira Baro Mestre em Ciências da Educação na Universidad Autónoma delSur - UNASUR/Paraguai. andreiabaro@hotmail.com
\end{abstract}

\begin{abstract}
Resumo - No âmbito regional, o Semiáridoalagoanonãoacompanhou o mesmodesenvolvimento no setorlácteo; em parte, porque o estadoaindapossuíaumapopulaçãourbanapequena, que aindanãodemandavaesseprocesso de industrialização. Assim, a produção de leite bovino os derivados lácteos no Semiárido do estado, ainda sustentavam-se com um caráter predominantemente de subsistência. (JÚNIOR, 2017, 105 p.). Dentro dos parâmetros analisados são perceptíveis as grandes divergências entre os dados socioeconômicos de cada um dos municípios da bacia leiteira do Sertão alagoano, ainda que a atividade leiteira tenha proporcionado melhorias, não foi o suficiente para alavancar a economia dentro do cenário produtivo e concorrencial.
\end{abstract}

Palavras-chave: Industrialização; Setor Lácteo; Cadeia Produtiva; Bacia Leiteira; Sertão Alagoano.

\section{ANALYSIS OF THE MILK PRODUCTION CHAIN IN THE LEITEIRA RIVER BASIN OF ALAGOANO IN THE PERIOD 1990 TO 2010}

\begin{abstract}
At the regional level, the Alagoan Semiarid did not follow the same development in the dairy sector; in part, because the state still possessed a small urban population, which still did not demand this process of industrialization. Thus, the production of bovine milk the dairy derivatives in the state's semi-arid, still supported themselves with a predominantly subsistence character. (JR, 2017, 105 pp.). Within the analyzed parameters, the great divergences between the socioeconomic data of each of the municipalities of the Alagoas sertão dairy basin are perceptible, although the dairy activity has provided improvements, it was not enough to leverage the economy within the productive and competitive scenario.
\end{abstract}

Keywords: Industrialization; Dairy Sector; Productive Chain; Dairy Basin; Backwoods Alagoan.

\section{INTRODUÇÃO}

A produção de leite é tão disseminada na agricultura familiar, porque as barreiras à entrada não são significativamente altas, o que possibilita o desenvolvimento dessa atividade por indivíduos com poucos recursos para investimento, e como, em geral, a família já produz leite para consumo interno, acaba destinando o leite restante para comercialização ou processamento. De qualquer forma, a atividade leiteira assume um papel importante para a agricultura familiar, que vai além da

\footnotetext{
${ }^{1}$ Artigo apresentado no XIII Congresso da Sociedade Brasileira de Economia, Administração e Sociologia Rural (SOBER NORDESTE, 2017), realizado em Juazeiro - Bahia.
} 
alimentação da família, já que permite a obtenção de uma renda mensal que, em geral, é utilizada para as despesas domésticas, ao contrário das demais atividades que são safristas.

A atividade leiteira permite ainda o uso de terras não-nobres para o seu desenvolvimento e utiliza de forma intensiva a mão-de-obra familiar. Por outro lado, a atividade leiteira tem grande importância na fixação do homem no campo, à medida que é a única atividade produtiva no meio rural que exige a presença da mão-de-obra todos os dias do ano, contribuindo para a redução do êxodo rural. (SOUZA, 2007, p. 14.). Além de diminuir com o êxodo rural, ainda possibilita o repasse de conhecimento em uma atividade e possibilita a organização de associações, permitindo o fortalecimento da atividade e da região onde a ação é desenvolvida.

Importante observar que se tratando do mercado de derivado de leite, é o mais consumido mundialmente e, sua produção a cada ano apresenta uma tendência de crescimento. De acordo FAO ${ }^{14}$, cerca de 150 milhões de lares em todo o mundo estão envolvidos na produção de leite. Na maioria dos países em desenvolvimento. $\mathrm{O}$ leite produzido por pequenos produtores contribui para a subsistência do agregado familiar, segurança alimentar e nutrição. $\mathrm{O}$ produto fornece retornos relativamente rápidos para os pequenos produtores, sendo uma importante fonte de renda. A produção mundial de leite aumentou em mais de 61\%, de aproximadamente de 482 milhões de toneladas em 1982 para 566 milhões de toneladas em 2014. No período de 2010 a 2014, o rebanho de vacas lactantes teve um crescimento anual de 0,55\%, passando de 246.509 milhões de cabeças para 251.942 milhões. Importante analisar que a diferença entre taxa de crescimento geométrico entre a variação da produção e do rebanho, tem uma relação direta dos ganhos de produtividade (SILVA, 2015, p. 43-44.).

O rebanho de vacas leiteiras no Brasil tem apresentado modesto crescimento na última década, apresentando crescimento de 0,39\% no período, alcançando um total de 211.764 milhões de Vacas ordenhadas em 2013. A produção de leite no Brasil apresentou a marca de 34 bilhões de litros, apresentando uma elevação na produção de 4,29\% nos últimos dez anos. Neste cenário, 75,5\% da oferta de derivado de leite de vaca são consumidas pelo mercado interno e apenas $24,5 \%$ da produção brasileira é direcionada para o mercado internacional.

Importante observar o crescimento das importações no ano 2013, apresentando um crescimento nos últimos dez anos de $12,19 \%$ ao ano e apresentando uma queda no mesmo período de $6,20 \%$. Diante da crise mundial a produção de leite no Brasil apresentou crescimento diante da produtividade (IBGE, 2013) apud (SILVA, 2015, p. 47).

Deve ser acrescentado que secas no Nordeste e em outras partes do país no período, abate exagerado de novilhas e exportação de vacas entre outros fatores induziram também a oferta de leite não conseguir acompanhar tão bem a demanda. Essa mesma demanda foi também aquecida por políticas sociais do governo como a bolsa família e processos de valorização do salário 
mínimo que levou um aumento de poder aquisitivo de classes sociais menos favorecidas, levando a um aumento do consumo per capita (DUARTE, 2000) apud (SILVA, 2015, p. 48.). É importante frisar esse apontamento realizado, pois se percebe que os programas sociais desenvolvidos pelo governo, de certa forma obtiveram o efeito desejado, permitindo uma maior demanda por parte da população, infelizmente, a oferta do leite passa a ser afetada diretamente por questões climáticas e de sazonalidade, as quais afetam a produção.

Seguindo a lógica de aumento da produção apontada no Nordeste, o documento desenvolvimento pela Embrapa, denominado Panorama do Leite, em 2015 apontou expressivos crescentes dessa atividade, onde o Estado de Alagoas apresentou um crescimento significativo de 20,8\% apenas em 2014, atingindo um total de 305 milhões de litros de leite, no mesmo período o Nordeste cresceu 8,1\% na produção de Leite (EMBRAPA, 2015, p. 5-6²).

Diante disso, o presente projeto de pesquisa pretende o setor lácteo especificamente no Estado de Alagoas, analisando como o desenvolvimento dessa atividade acabou gerando expressivamente o aumento na produção seja de leite, seja de gado. Com isso, surge como problema de pesquisa: $\mathrm{O}$ desenvolvimento da atividade leiteira tem apresentando expansão em Alagoas, seguindo a lógica do Nordeste?

Seguindo o presente problema de pesquisa, temos os objetivos a serem apontados: Analisar a atividade do setor lácteo no Estado de Alagoas, em decorrência desse objetivo geral, surgem demais objetivos específicos: a) Verificar o aumento na produção de leite em Alagoas; b) Verificar o aumento de gado; c) Analisar se na região da bacia leiteira tivemos modificações significativas em taxas de desenvolvimento.

\section{AS VISÕES DA ECONOMIA QUANTO AO SENTIDO DO DESENVOLVIMENTO LOCAL}

Batalha (2009, p. 26-27) enaltece a importância da tecnologia, sua contribuição para o surgimento de novos produtos e a sua influência frente às estratégias das firmas para que possa dominar o mercado com plena interação entre suas atividades. A tecnologia desempenha um papel cada vez mais importante como fator explicativo das estruturas industriais e do comportamento competitivo das firmas. pode-se observar, ao longo dos últimos anos, uma explosão no numero de produtos disponíveis aos consumidores em todos os setores de atividades. Lambin (1991) afirma que em empresas de sucesso 40 a $60 \%$ do faturamento são realizados por produtos que há cinco

\footnotetext{
${ }^{2}$ EMBRAPA. Panorama do Leite, Ano 7, $\mathrm{n}^{\mathrm{o}} 75$, Outubro de 2015 . Disponível em:<https://www.embrapa.br/documents/1355117/1528925/Panorama+do+Leite+-+outubro+2015/997da482-483f-4451-bd26e9f7e1d95c4b> Acesso em: 10 de Mai. 2017.
} 
anos inexistiam no mercado. Este fato evidencia a importância de integrar o estudo das inovações tecnológicas no conjunto das ações de reflexão estratégica das firmas.

Seguindo o pensamento destacado no parágrafo anterior, Schumpeter (1982), contribui com esse discurso apontando sobre o papel da empresa inovadora, onde o papel dessa é o de contestar o equilíbrio existente nas estruturas industrias, a própria mudança das regras do jogo de forma concorrencial.

É nesse contexto, que Batalha (2009), aponta para o fato de que a análise das cadeias de produção, dentro de uma ótica sistêmica de ação acaba influenciando direta e indiretamente as firmas, o que de certa forma se ajusta com a análise schumpeteriana, sendo a ótica sistêmica necessária para isso.

Devemos pensar ainda na ideia de ciclo de vida, onde podemos verificar a existência desse ciclo na cadeia agroindustrial, seguindo a ideia do ciclo de vida de produtos. O que acaba em determinado momentos de queda, sendo necessária a busca por parte dos agentes de dentro da cadeia por novos produtos e ações que possam manter o sistema vivo e atuante, evitando a fase de declínio. Afinal, a fase de declínio não afeta apenas membros internos a cadeia produtiva, mas também membros externos, tendo em vista que os agentes atuam dentro de um contexto sistêmico, agentes fora da cadeia são afetados direta ou indiretamente. Batalha (2009, p. 28) em seu trabalho demonstra essa preocupação, quando o mesmo afirma que:

\begin{abstract}
A representação de um sistema produtivo em termos de cadeia de produção adapta-se muito bem como ferramenta de estudo para identificar, por exemplo, as perturbações criadas a montante e a jusante da inovação original. Este tipo de análise pode ir ainda mais longe na medida em que permite avaliar as consequências das inovações não somente no interior da cadeia de produção delimitada como espaço analítico inicial (análise vertical), mas também junto a outras cadeias de produção que com ela se interconectam (análise horizontal). Neste caso, a noção de "operações-nó" pode ser utilizada.
\end{abstract}

Além dessa situação apontada, podemos identificar ainda outros fatores que vão desde os fatores econômicos, os quais acabam envolvendo variáveis endógenas e exógenas a cadeia produtiva e ao contexto regional, como também podemos citar fatores socioculturais, legais e jurídicos, além de fatores políticos que acabam influenciando de alguma forma.

Corroborando ainda para a discussão do papel da empresa inovadora, é possível destacar que a ação de inovar atinge a cadeia de produção de forma tão impactante que as varias etapas são influenciadas, atingindo características transversais. No caso do setor lácteo, o processo de inovação pode vir a atingir não apenas pela forma de organização e desenvolvimento do manejo, mas também no processo de embalagem, transformação, assim como na distribuição do produto. Entretanto, o setor ainda é destacado como um dos que menos investem, conforme aponta Batalha (2009, p. 30), 
por isso, que as inovações obtidas nesse setor são desenvolvidas por empresas que não estão diretamente envolvidas no fluxo de transformação.

\section{CADEIAS AGROALIMENTARES E AGROINDUSTRIAIS}

Considerando o que preconiza Morvan (1985), o que está implicitamente ligada à cadeia produtiva agroindustrial é a visão de uma sucessão de operações de transformação dissociáveis que podem ser ligadas ou separadas por um encadeamento técnico entre si, tendo um conjunto de relações comerciais e financeiras que estabelecem um fluxo de troca de montante a jusante e entre fornecedores e clientes e, tem como suporte ações econômicas que promovem a valoração dos meios de produção e asseguram a articulação das operações. (PAES et al., 2009, p. 05).

De forma mais operacional Batalha et al (1997) divide a cadeia produtiva agroindustrial nos segmentos de comercialização; industrialização e produção de matérias-primas. No segmento da comercialização encontram-se as empresas que estão em contato com o cliente final da cadeia de produção e que viabilizam o consumo e o comércio dos produtos finais (supermercados, mercearias, restaurantes e cantinas), incluindo nesse segmento as empresas responsáveis somente pela logística de distribuição; no segmento da industrialização estão localizadas as empresas responsáveis pela transformação das matérias-primas em produtos finais destinados ao consumidor, destaca que o consumidor pode ser uma unidade familiar ou outra agroindústria e, no segmento da produção de matérias-primas estão as empresas rurais que fornecem as matérias primas oriundas da agricultura, pecuária e piscicultura para que outras empresas as transformem em produtos finais utilizando-se de processos de produção automatizados ou não. (PAES et al., 2009, p. 05).

É primordial para a cadeia produtiva do leite a melhoria da sua competitividade, a partir do desenvolvimento e modernização da agroindústria que iniciou a transformação do setor, e isso requer dos demais segmentos da cadeia, modernização através de inovações tecnológicas, visando sempre o desempenho competitivo, e este somente será possível, se houver a consciência de todos os integrantes da necessidade de maior integração e melhor coordenação da cadeia. (PAES et al., 2009, p. 07).

No entorno da cadeia encontra-se os ambientes institucional e organizacional e ainda, os setores de suporte, que consistem nas atividades indiretas e complementares ao objetivo da cadeia. Elas fornecem os meios para o desenvolvimento das atividades dos segmentos principais e as opções técnicas e comerciais necessárias à produção dos bens. Com o entendimento de que uma cadeia produtiva é dinâmica, tem-se presente, entretanto, que as relações com o mercado por todos os segmentos são determinantes para a sua competitividade. A forma dinâmica de conceber a cadeia produtiva possibilita que se identifique a característica e se visualize as condições dos segmentos principais e os setores de suporte da cadeia. (PAES et al., 2009, p. 05). 
Destaca-se a importância e a influência dos atores relacionados com as atividades de suporte, considerando que a dinâmica da cadeia agroindustrial em seus aspectos de qualidade e competitividade depende do desempenho dos setores de apoio. Como atividades de apoio à cadeia, inseridas no setor de suporte, pode-se citar: o sistema financeiro; as indústrias de embalagens, de aditivos, de implementos, de equipamentos, inspeção sanitária, transporte, $\mathrm{P} \& \mathrm{D}$, sistema de comunicação e associações, os quais podem impactar de maneira decisiva os vários elos da cadeia produtiva. (PAES et al., 2009, p. 05).

\section{A BACIA LEITEIRA ALAGOANA}

Localizado no Sertão e Agreste alagoano com um território de $5.053 \mathrm{~km}^{2}$, fazem parte da bacia leiteira os municípios de: Batalha, Belo Monte, Cacimbinhas, Dois Riachos, Estrela de Alagoas, Igaci, Jacaré dos Homens, Jaramataia, Major Isidoro, Minador do Negrão, Monteirópolis, Olho D’ água das Flores, Olivença, Palmeira dos Índios, Pão de Açúcar, Santana do Ipanema e São José da Tapera. Essas 17 cidades constituíram juntas em 1990 o maior centro produtor de leite in natura do Nordeste brasileiro, sua atividade considerada como uma das mais importantes na economia do estado, perdendo espaço apenas para o cultivo de cana-de-açúcar, e também para os municípios pertencentes à bacia leiteira, uma vez que se houver uma fragilização nessa atividade, leva junto o bom desempenho do comércio local, ocasionando crises, consequentemente o poder de compra da população diminui, por grande parte dos empregos e renda das famílias dependerem dessa cadeia produtiva.

A atividade leiteira se desenvolveu com o passar dos anos, sua produção já existia bem antes de 1990 nessa região, a qual passou por grandes transformações a partir desse mesmo ano, sofrendo grandes mudanças para se enquadrar as novas exigências impostas pelo mercado, advindas da revolução industrial a qual o Brasil estava adotando para que pudesse concorrer frente às grandes multinacionais.

Entre 1998 e 2003, o Banco do Nordeste financiou a criação do polo da bacia leiteira, em uma área de 5.053,2 km², objetivando o desenvolvimento regional, em 17 municípios do semiárido alagoanos, com condições naturais e potencialidades socioeconômicas parecidas (CARNEIRO, 2005, p. 13, 62, 88; BNB, s/d). (JÚNIOR, 2015, p. 6205).

A cadeia produtiva proporcionou ao longo dessas duas décadas, grandes avanços para os municípios, foram aplicados recursos federais, uma vez que as sazonalidades existentes, a principal delas, e mais castigante é a seca, através dela surgem muitos outros problemas externos, impedindo o desenvolvimento da atividade leiteira, Junior (2015, p. 6027) destaca melhorias para a região da bacia leiteira entre os anos 90 até 2010, não deixando de explicitar os agravantes que ocasionaram o estancamento da atividade, a politica regente a qual estava subordinada os produtores que participam ativamente dessa empregabilidade: 
Os indicadores sociais alagoanos tiveram discretas melhorias, entre 1991 e 2010, graças aos investimentos federais. Em 2010, a média dos índices de população urbana, IDHM, mortalidade infantil, GINI e pobreza, correspondente a uma população de 330.308 habitantes, dos 17 municípios da região deprimida do polo leiteiro, foram piores do que os indicadores de Alagoas, do Nordeste e do Brasil (PNUD, s/d). A situação social dos municípios da bacia leiteira possui relação direta com a condição política coronelista e latifundiária da região, estruturada no paternalismo dos maiores fazendeiros produtores de leite (MDA, 2011, p. 19, 20). (JÚNIOR, 2015, p. 6207).

\section{O CONCEITO DE ARRANJO PRODUTIVO LOCAL E SEU PAPEL NO DESENVOLVIMENTO LOCAL}

Os dados do Censo agropecuário do IBGE, para Alagoas, revelam que o efetivo de bovinos (corte e leite) aumentaram 71,61\%, de 1970 para 1995, enquanto que a produção de leite bovino in natura aumentou 338,03\% - associados ao aumento da urbanização. Entre 1995 e 2006, porém, os bovinos apresentaram quedas de 8,48\% nos rebanhos (corte e leite) e 7,70\% na produção de leiteira, decorrentes de mais um período de seca.

De acordo com levantamento do IBGE, em 2008 o rebanho de bovinos em Alagoas era composto por 1.162.005 cabeças, o de ovinos somava 193.686, e o de caprinos era de 64.721. Em 2010, Alagoas somava 170.050 cabeças de vacas, o que representava 3,86\% da região Nordeste e 0,79\% do Brasil. (JÚNIOR et al., 2013, p. 07).

A interação gerada pela atividade econômica leiteira permitiu o seu crescimento ao longo dos anos, pelo viés a qual apresenta Almeida (2012, p. 19):

\footnotetext{
"O Estado de Alagoas é o sexto produtor da região Nordeste ficando abaixo da Bahia, que tem o maior rebanho com 10,2 milhões de cabeça, de Pernambuco, do Ceará, do Maranhão e de Sergipe. Em 31/12/2010 o Estado tinha 1.219.578 cabeças, representando 0,6 do rebanho nacional de gado de leite e de corte. Durante o ano de 2010 foram ordenhadas 149.411 vacas, com média de produção de 1.549 litros/vaca/ano, produzindo 231.367.000 litros de leite, representando 0,8\% da produção nacional, com um valor de R\$ 148.886.000,00 (BRASIL, 2011a)”.
}

A cadeia de laticínios no estado tem grande notoriedade, mas denota fragilidade no conjunto de agentes econômicos que a rege, suas etapas de produção não são favorecidas dentro de seu espaço geográfico, envolvendo uma série de fatores endógenos e exógenos, interferido diretamente sobre sua estrutura no plano concorrencial.

Segundo Almeida (2012, p. 15). A produção de leite em Alagoas é a segunda atividade econômica mais importante do Estado, perdendo apenas para a cana-de-açúcar, e se concentra na bacia leiteira do Estado, no sertão e agreste alagoano (DANTAS, 2011). Apesar das exigências de qualidade e aumento da população, o Estado de Alagoas continua com baixos índices de produção e produtividade, quando comparado aos estados do Paraná, Rio Grande do Sul, Santa Catarina, Minas Gerais e ao Distrito Federal. Mesmo 
apresentando uma bacia leiteira considerada importante para o nordeste brasileiro, sendo, segundo SEBRAE (2010), a quarta maior bacia leiteira da região. (ALMEIDA, 2012, p. 12).

\title{
PRODUÇÃO DE LEITE EM ALAGOAS
}

Analisando a produção de leite, no estado de Alagoas a nível Nordeste entre os anos de 1990 a 2007, se tem uma classificação de maior produtor o estado da Bahia, com uma produção total de 13.661.654 litros, alcança seu auge produtivo em 2007. Alagoas durante esse intervalo de tempo fica em $4^{\circ}$ lugar, sua produção total é de 4.009.771 litros, registrando sua maior produção em 1997. O polo da Bacia Leiteira do estado de Alagoas é o maior centro produtor de leite in natura do Nordeste, com aproximadamente 2.500 produtores rurais, gerando 25.000 empregos diretos. Consta de 17 municípios, Batalha, Belo Monte, Cacimbinhas, Dois Riachos, Estrela de Alagoas, Igaci, Jacaré dos Homens, Jaramataia, Major Izidoro, Minador do Negrão, Monteirópolis, Olho D’água das Flores, Olivença, Palmeira dos Índios, Pão de Açúcar, Santana do Ipanema e São José da Tapera (BNB, 2005). (ALMEIDA, 2012, p. 28).

Apesar de ser localizada no sertão alagoano, uma região muito castigada pelas estiagens prolongadas, o clima é o grande influenciador das atividades produtivas, diante desse contexto é importante ressaltar que:

\begin{abstract}
[...] Em 1990, a bacia leiteira do Estado formava o maior centro produtor in natura de leite da Região Nordeste. Dados da Secretaria de Planejamento e Desenvolvimento do Estado mostram que atualmente essa atividade enfrenta problemas de competitividade concentrados no segmento de pequenos produtores, o que pode ser constatado com a queda de aproximadamente $30 \%$ na produção de leite nos últimos anos. A indústria do leite é de extrema importância para o Estado, especialmente na economia dos municípios integrantes da bacia leiteira. O fato é que quando a produção está fragilizada toda a economia dos municípios é afetada, gerando séria crise no comércio local. (JÚNIOR et al., 2013, p. 07).
\end{abstract}

Os 17 municípios da região do polo leiteiro, se distribuíram entre as mesorregiões do Sertão e Agreste do semiárido alagoano do Nordeste, que segundo Ab'Sáber (1999, p. 7, 10, 32) é caracterizada por uma combinação de fatores ambientais, com baixos níveis de umidade, escassez de chuvas, precipitações anuais desreguladas, carência hídrica, solos pobres - salinos e carbonáticos, rios intermitentes, vegetação arbustiva-arbórea quase totalmente caducifólia com folhas miúdas e hastes espinhentas adaptadas aos efeitos da evapotranspiração. (JÚNIOR, 2015 , p. 6200). Reforçando a ideia dos diversos aspectos típicos que interferem diretamente na atividade econômica leiteira a qual desempenha essa região.

Os indicadores sociais das 17 cidades revelam quais são os fatores exigidos para exercerem maiores destaques dentro da cadeia produtiva do leite. 
Tabela 01. Índices Sociais dos municípios da bacia leiteira do sertão alagoano

\begin{tabular}{|c|c|c|c|c|}
\hline Município & População (hab.) & Área $\left(\mathrm{km}^{2}\right)$ & IDHM & PIB (R\$) \\
\hline Batalha & 17.076 & 319,499 & 0,594 & $4.027,68$ \\
\hline Belo Monte & 7.030 & 333,259 & 0,517 & $5.285,37$ \\
\hline Cacimbinhas & 10.195 & 273,767 & 0,531 & $4.112,70$ \\
\hline Dois Riachos & 10.880 & 139,853 & 0,532 & $3.519,77$ \\
\hline Estrela de Alagoas & 17.251 & 260,772 & 0,534 & $3.354,51$ \\
\hline Igaci & 25.188 & 334,754 & 0,564 & $4.166,74$ \\
\hline Jacaré dos Homens & 5.413 & 149,501 & 0,583 & $5.469,56$ \\
\hline Jaramataia & 5.558 & 103,714 & 0,552 & $4.479,68$ \\
\hline Major Isidoro & 18.897 & 448,847 & 0,566 & $4.602,25$ \\
\hline Minador do Negrão & 5.275 & 167,604 & 0,563 & $4.784,78$ \\
\hline Monteirópolis & 6.935 & 86,604 & 0,539 & $3.683,86$ \\
\hline Olho d'Água das Flores & 20.364 & 191,323 & 0,565 & $4.712,46$ \\
\hline Olivença & 11.047 & 175,709 & 0,493 & $3.811,65$ \\
\hline Palmeira dos Índios & 70.368 & 450,958 & 0,638 & $6.305,93$ \\
\hline Pão de Açúcar & 23.811 & 693,692 & 0,593 & $3.985,90$ \\
\hline Santana do Ipanema & 44.932 & 437,878 & 0,591 & $5.477,67$ \\
\hline São José da Tapera & 30.088 & 494,498 & 0,527 & $3.514,30$ \\
\hline
\end{tabular}

Fonte: IBGE, dados referente ao ano de 2010. Fonte: Próprio Autor

Toda extensão territorial a qual faz parte a bacia leiteira é de $5.053 \mathrm{~km}^{2}$, os IDHM apresentados estão classificados entre muito baixo (atribuído a Olivença) e médio. Palmeira dos Índios possuem os melhores indicadores sociais, com exceção apenas para sua área territorial, ocupando o $3^{\circ}$ lugar dessa categoria e Pão de Açúcar o $1^{\circ}$.

Contemplaram grandes destaques na produção de leite da bacia leiteira, Batalha, Palmeira dos Índios, Jacaré dos Homens Major Isidoro e Belo Monte; As quais foram dominantes na atividade produtivas de leite: Palmeira dos Índios por possuir melhores indicadores sociais, se situa como o $2^{\circ}$ maior produtor de leite.

Apesar de apenas cinco das cidades se destacarem na escala definida, não diminui a importância das demais, atrelando sua contribuição na composição da cadeia produtiva, uma vez que devem ser levados em consideração todos os fatores que interferem para o bom desempenho e capacidade produtiva de cada uma delas. Semelhantes dados apresentados na tabela 02 : 
Tabela 02 - Produção de Leite (mil 1) - Principais Cidades produtoras da Bacia Leiteira (1990-2010).

\begin{tabular}{|c|c|c|c|c|c|}
\hline Ano & Batalha & $\begin{array}{c}\text { Palmeira dos } \\
\text { Índios }\end{array}$ & $\begin{array}{c}\text { Jacaré dos } \\
\text { Homens }\end{array}$ & Major Isidoro & Belo Monte \\
\hline 1990 & 9850.00 & 19519.00 & 4487.00 & 8332.00 & 3574.00 \\
\hline 1991 & 32967.00 & 18965.00 & 20775.00 & 8582.00 & 3972.00 \\
\hline 1992 & 35152.00 & 20908.00 & 22095.00 & 8500.00 & 4473.00 \\
\hline 1993 & 31538.00 & 16727.00 & 19822.00 & 8465.00 & 3059.00 \\
\hline 1994 & 32484.00 & 16905.00 & 20448.00 & 8607.00 & 3303.00 \\
\hline 1995 & 35734.00 & 16988.00 & 22472.00 & 8650.00 & 3616.00 \\
\hline 1996 & 42881.00 & 18291.00 & 25843.00 & 8757.00 & 3730.00 \\
\hline 1997 & 35303.00 & 18356.00 & 28731.00 & 8914.00 & 31759.00 \\
\hline 1998 & 27907.00 & 17989.00 & 19460.00 & 9729.00 & 21076.00 \\
\hline 1999 & 27555.00 & 15419.00 & 17008.00 & 7783.00 & 16522.00 \\
\hline 2000 & 27997.00 & 15518.00 & 18397.00 & 8116.00 & 13898.00 \\
\hline 2001 & 32923.00 & 15232.00 & 19555.00 & 8213.00 & 21257.00 \\
\hline 2002 & 32044.00 & 15210.00 & 9997.00 & 8213.00 & 10993.00 \\
\hline 2003 & 36100.00 & 15213.00 & 10200.00 & 8243.00 & 12500.00 \\
\hline 2004 & 28000.00 & 15214.00 & 11000.00 & 8618.00 & 10000.00 \\
\hline 2005 & 20100.00 & 15250.00 & 8000.00 & 9293.00 & 7000.00 \\
\hline 2006 & 14000.00 & 15395.00 & 9000.00 & 9837.00 & 5400.00 \\
\hline 2007 & 14000.00 & 15500.00 & 7500.00 & 8500.00 & 5972.00 \\
\hline 2008 & 12000.00 & 13440.00 & 8700.00 & 12000.00 & 5061.00 \\
\hline 2009 & 10500.00 & 11600.00 & 9000.00 & 15600.00 & 4800.00 \\
\hline 1010 & 10100.00 & 12180.00 & 8700.00 & 16640.00 & 4200.00 \\
\hline
\end{tabular}

Fonte: IBGE/PPM - Dados anuais por Estado da Federação e do Brasil de 1974 a 2015, Embrapa Gado de Leite e SEAPA-MG 2017. Elaboração: Próprio Autor

No recorte regional, a bacia leiteira alagoana possui um rebanho de 120 mil matrizes, distribuídas em 4.500 produtores, os quais produzem, em média, 690.000 litros de leite/dia, distribuídos em 21 municípios, com destaque para Major Isidoro e Batalha. Segundo a Federação das Indústrias do Estado de Alagoas (2010), essa indústria possui 154 empresas, distribuídas em todo território alagoano, sobretudo nas mesorregiões do agreste e sertão, que possuem vocação econômica e tradição nessa atividade, e capacidade de geração de emprego e renda ao longo da cadeia. (JÚNIOR et al., 2013, p. 02).

Seguindo o que está sendo pautado é perceptível o quanto essas cidades conquistaram avanços produtivos, visto que, Batalha, Major Isidoro, Santana do Ipanema, Igaci e Batalha, dispõem do maior efetivo de bovinos de toda a bacia leiteira, examinada no transcorrer dos anos 90 e 2000. A tabela 03 contabiliza dados dessas cidades destaques: 
Tabela 03 - Quantidade Efetiva de Bovinos - Principais Cidades produtoras da Bacia Leiteira (1990-2010).

\begin{tabular}{|c|c|c|c|c|c|}
\hline Ano & $\begin{array}{c}\text { Palmeira dos } \\
\text { Índios }\end{array}$ & $\begin{array}{c}\text { Major } \\
\text { Isidoro }\end{array}$ & $\begin{array}{c}\text { Santana do } \\
\text { Ipanema }\end{array}$ & Igaci & Batalha \\
\hline 1990 & 43.784 & 25.208 & 41.160 & 18.826 & 15.520 \\
\hline 1991 & 43.959 & 25.712 & 47.531 & 19.102 & 22.643 \\
\hline 1992 & 44.338 & 25.455 & 49.908 & 18.911 & 26.039 \\
\hline 1993 & 35.729 & 25.220 & 19.966 & 18.994 & 23.435 \\
\hline 1994 & 36.086 & 25.346 & 21.763 & 19.133 & 25.075 \\
\hline 1995 & 36.266 & 25.469 & 23.610 & 19.229 & 27.583 \\
\hline 1996 & 36.628 & 25.723 & 25.735 & 18.845 & 30.341 \\
\hline 1997 & 36.809 & 25.594 & 22.600 & 19.976 & 19.245 \\
\hline 1998 & 36.588 & 25.096 & 20.340 & 20.048 & 15.396 \\
\hline 1999 & 34.395 & 20.584 & 16.272 & 19.647 & 12.317 \\
\hline 2000 & 34.379 & 21.202 & 12.692 & 19.816 & 13.548 \\
\hline 2001 & 34.550 & 21.414 & 13.327 & 19.896 & 17.612 \\
\hline 2002 & 34.777 & 21.220 & 14.926 & 19.803 & 15.442 \\
\hline 2003 & 34.174 & 21.220 & 15.126 & 18.902 & 15.830 \\
\hline 2004 & 34.344 & 21.328 & 16.500 & 18.600 & 16.000 \\
\hline 2005 & 37.092 & 27.547 & 21.329 & 18.420 & 17.280 \\
\hline 2006 & 37.277 & 27.823 & 21.561 & 18.300 & 15.917 \\
\hline 2007 & 38.000 & 29.000 & 24.000 & 20.130 & 17.500 \\
\hline 2008 & 41.140 & 28.563 & 25.000 & 21.136 & 17.300 \\
\hline 2009 & 41.140 & 28.563 & 25.700 & 23.038 & 17.000 \\
\hline 2010 & 41.400 & 29.080 & 25.695 & 23.160 & 16.500 \\
\hline
\end{tabular}

FONTE: Instituto Brasileiro de Geografia e Estatística / IBGE - Pesquisa Pecuária Municipal / PPM - SEPLAND E-AL, acessado em setembro de 2017. Elaboração: Próprio Autor

$\mathrm{Na}$ liderança do ranking de maiores produtores de bovinos da bacia leiteira do sertão alagoano, as cidades de Palmeiras dos Índios, Major Isidoro, Santana do Ipanema, Igaci e Batalha; entre 1990 a 2007, nesses munícipios se concentravam os maiores rebanhos dessa região. Palmeira dos Índios liderou o maior rebanho, em 2001 e 2002 Santana do Ipanema chegou a ocupar essa liderança, não se perpetuando, já que no ano seguinte a sua antecessora voltaria ao patamar da qual foi destituída pelas estáticas.

Já a cidade de Batalha lideraria por todos esses anos a produção no setor lácteo, atingido o ápice produtivo em 1997, sofreu após essa data oscilações em seu volume produzido, vindo a baixar gradativamente, quase que se igualando as demais cidades, as quais se mantiveram constantes em seus crescimentos, demostrando uma leve acentuada em seus percentuais ao longo do período.

Batalha, Jacaré dos Homens, Major Isidoro e Belo Monte ganham destaque como detentoras da maior quantidade efetiva de vacas ordenhadas, seguindo a ordem estabelecida através dos seus indicadores se percebe qual foi o ano de melhor rendimento, as flutuações e estagnações nos resultados gerados, em todo esse percurso. 
Tabela 04 - Quantidade efetiva de Vacas Ordenhadas - Principais Cidades produtoras da Bacia Leiteira (1990-2010).

\begin{tabular}{|l|l|l|l|l|l|}
\hline \multicolumn{1}{|c|}{ Ano } & \multicolumn{1}{|c|}{ Batalha } & \multicolumn{1}{c|}{$\begin{array}{c}\text { Jacaré dos } \\
\text { Homens }\end{array}$} & $\begin{array}{c}\text { Palmeira dos } \\
\text { Índios }\end{array}$ & Major Isidoro & Belo Monte \\
\hline 1990 & 5.750 & 2.645 & 8.913 & 5.707 & 2.264 \\
\hline 1991 & 18.315 & 11.573 & 9.447 & 5.878 & 4.041 \\
\hline 1992 & 19.529 & 12.275 & 9.547 & 5.822 & 4.550 \\
\hline 1993 & 18.552 & 11.660 & 7.638 & 5.798 & 4.095 \\
\hline 1994 & 19.108 & 12.018 & 7.714 & 5.855 & 4.422 \\
\hline 1995 & 21.020 & 13.219 & 7.791 & 5.884 & 4.820 \\
\hline 1996 & 23.122 & 14.542 & 8.492 & 5.998 & 5.109 \\
\hline 1997 & 16.120 & 11.245 & 8.537 & 6.118 & 12.430 \\
\hline 1998 & 13.700 & 9.558 & 8.449 & 6.949 & 10.538 \\
\hline 1999 & 11.998 & 9.565 & 8.449 & 5.689 & 10.678 \\
\hline 2000 & 12.194 & 10.347 & 8.503 & 5.917 & 8.984 \\
\hline 2001 & 15.242 & 10.864 & 8.462 & 5.976 & 11.230 \\
\hline 2002 & 14.835 & 6.554 & 8.449 & 5.976 & 6.810 \\
\hline 2003 & 15.400 & 8.904 & 8.490 & 6.000 & 6.815 \\
\hline 2004 & 10.000 & 6.000 & 8.570 & 6.250 & 5.500 \\
\hline 2005 & 7.000 & 5.000 & 8.590 & 7.500 & 3.900 \\
\hline 2006 & 6.900 & 7.500 & 8.700 & 7.000 & 3.200 \\
\hline 2007 & 12.744 & 7.000 & 8.900 & 7.000 & 3.540 \\
\hline 2008 & 5.500 & 5.000 & 7.000 & 7.300 & 3.000 \\
\hline 2009 & 4.800 & 4.100 & 6.000 & 7.700 & 2.700 \\
\hline 2010 & 4.400 & 3.800 & 6.300 & 8.000 & 2.500 \\
\hline
\end{tabular}

Fonte: IBGE/PPM - Dados anuais por Estado da Federação e do Brasil de 1974 a 2015, Embrapa Gado de Leite e SEAPA-MG 2017. Elaboração: Próprio Autor

Seguindo uma linha concorrencial foram destacadas as cidades anteriormente citadas, adiante se posiciona Santana do Ipanema, Pão de Açúcar, Igaci, Cacimbinhas, Jaramataia, São José da Tapera, Minador do Negrão, Olivença, Dois Riachos, Estrela de Alagoas, Olho d'Água das Flores e Monteirópolis. Batalha é apontada como a cidade que possuiu a maior quantidade de vacas ordenhadas em todo o período analisado, atingindo 23.122 em 1996, em 2005 e 2006 perde o território para Major Isidoro e Palmeira dos Índios, voltando ao topo em 2007, para nos anos seguintes decair e não mais atingir a colocação conquistada.

Jacaré dos Homens toma posse em segundo lugar, onde atingiram 14.542 vacas ordenhadas em 1996, esse número declina a partir de 1997, e Belo Monte domina a quantidade de vacas ordenhadas até 2002, uma vez que não conseguiu se sustentar pelos anos seguintes, assim Jacaré dos Homens a ultrapassa, continuando seu crescimento até 2003, já em 2004 diminui seus números até o ano 2010. 
Palmeira dos Índios tem sua maior quantidade de vacas ordenhadas em 1992, essa parcela é reduzida de 1993 a 1995, se elevando e mantendo-se estável entre 1996 a 2007, reduzindo pelos anos seguintes. Olho D'água das Flores mais uma vez sofre declínio no quesito desempenho produtivo, ocupando o penúltimo lugar, e detém um pouco mais do numero de vacas ordenhadas, ganhando colocação no ranking apenas para Monteirópolis.

\section{CONCLUSÃO}

A presente pesquisa, embora tenha atingido seus objetivos inicias, analisando a evolução e competitividade da cadeia produtiva do leite, baseado na comparação com a evolução do estado de Alagoas, a qual possui uma das mais importantes bacia leiteira do Nordeste, localizada em uma região crítica, apresentando os menores índices de desenvolvimento e o menor rendimento econômico, porém sua atividade agrega grande importância para a economia, como a segunda atividade maior atividade econômica estadual.

Mesmo que atividade leiteira tenha sido desenvolvida em condições precárias, onde poderia ter havido uma melhor gestão na alocação e distribuição de recursos, descentralizando os poderes, de caráter paternalista, uma vez que já eram tão afetadas pelos problemas climáticos, intrínsecos da região a qual a bacia leiteira do sertão alagoano pertencia, as disparidades vão além de fenômenos naturais e estatísticos.

Quanto à importância do leite para o Estado de Alagoas, pouco existe em publicações científicas a respeito do assunto, contudo, no Nordeste, em 2010, segundo Brasil (2011a), os Estados da Bahia, Pernambuco e Ceará lideram a lista dos maiores produtores, com aproximadamente 2,6 bilhões de litros por ano. Em Alagoas a produção de leite é oriunda, principalmente, da agricultura familiar e a produção está estimada em 231 milhões de litros por ano. Pernambuco, Alagoas e Sergipe possuem o maior volume de leite produzido por área. Em todo Brasil estes estados só perdem para o Paraná e Santa Catarina em produção de leite por área (VILELA, 2011). (ALMEIDA, 2012, p. 15).

Analisando a produção de leite e gado, dentro da micro região de Alagoas, se destacam como os maiores produtores às cidades de: Batalha, Palmeira dos índios e Santana do Ipanema, se destacam com potencial produtivo não apenas para a bacia leiteira das quais fazem parte, são referências para todo o estado.

Outra dura realidade para pecuária no sertão são os péssimos indicadores sociais, embora mesmo ao longo dos anos tenha alcançado alguma melhora, mas não o suficiente para conseguir se reajustar a um bom nível, a qual deveria ter sido estabelecida metas e políticas voltadas a 
melhorar os índices, consequentemente grandes melhorias produtivas e regionais seriam alcançadas, já quem nem todas as cidades correspondem com um mesmo perfil.

Maior população: Palmeira dos Índios, Santana do Ipanema, São José da Tapera, Igaci, Pão de Açúcar, Olho D’água das Flores, Major Isidoro, Estrela de Alagoas e Batalha; menor número de habitantes: Olivença, Dois Riachos, Cacimbinhas, Belo Monte, Jaramataia, Jacaré dos Homens e Minador do Negrão.

Maior área territorial em km²: Pão de Açúcar, São José da Tapera, Palmeira dos Índios, Major Isidoro, Santana do Ipanema, Igaci, Belo Monte, Batalha, Cacimbinhas, Estrela de Alagoas e Olho D'água das Flores; menor proporção territorial $\mathrm{km}^{2}$ : Olivença, Minador do Negrão, Jacaré dos Homens, Dois Riachos, Jaramataia e Monteirópolis.

Maior IDHM - Índices de Desenvolvimento Humano: Palmeira dos Índios, Batalha, Pão de Açúcar Santana do Ipanema, Jacaré dos Homens, Olho D’água das Flores e Igaci; menor IDHM: Igaci, Minador do Negrão, Jaramataia, Monteirópolis, Estrela de Alagoas, Dois Riachos, Cacimbinhas, São José da Tapera, Belo Monte e Olivença.

Maior renda per capita: Palmeira dos Índios, Santana do Ipanema, Jacaré dos Homens, Belo Monte, Minador do Negrão, Olho D’água das Flores, Major Isidoro, Jaramataia e Igaci; menor renda per capita: Cacimbinhas, Batalha, Pão de Açúcar, Olivença, Monteirópolis, Dois Riachos, São José da Tapera e Estrela de Alagoas.

A realidade dos indicadores sociais determina apenas em partes, qual município vai apresentar a maior produção de leite, uma vez que somente dois deles apresentaram o perfil dentro das categorias as quais são analisadas, os municípios que se apresentam como os mais populosos e produtivos são: Palmeira, Santana do Ipanema com a terceira colocação de maior produtor de leite da bacia leiteira, e segunda colocação de maior população, Palmeira dos Índios ganha à terceira colocação no quesito de maior produtor de leite da bacia leiteira e maior área territorial.

Quando se trata de IDHM nos municípios da bacia leiteira, os dois maiores produtores de leite dessa região, Palmeira dos Índios que é o segundo maior produtor e com o maior percentual da categoria IDHM e Batalha o maior produtor de leite da bacia leiteira e o segundo na categoria IDHM, ambos deixam visível o domínio em ambas as categorias, confirmando através disso que os municípios com maior IDHM são aqueles de determinam seu poder de produção, não se limitando apenas as categorias citadas, e mais uma vez contemplam as primeiras colocações no PIB, surpreendentemente Jacaré dos Homens lidera o terceiro lugar nessa categoria, onde na categoria IDHM manteve o quinto lugar no ranking, mas sendo classificado com a menor população (hab.) e menor área $\left(\mathrm{km}^{2}\right)$. 


\section{REFERÊNCIA BIBLIOGRAFICA}

Organização das Nações Unidas para Alimentação e Agricultura - FAO. Disponível em: <http://www.fao.org/agriculture/dairy-production/en/\#.UwO_cmJdU40.> Acesso em 17 de novembro de 2014.

EMBRAPA. Panorama do Leite, Ano 7, $\mathrm{n}^{\mathrm{o}}$ 75, Outubro de 2015. Disponível em: <https://www.embrapa.br/documents/1355117/1528925/Panorama+do+Leite+outubro+2015/f97da482483f-4451-bd26-e9f7e1d95c4b> Acesso em: 10 de Mai. 2017

. Instituto Brasileiro de Geografia e estatística - IBGE. Índice de Desenvolvimento Humano Municipal - $\quad$ IDHM. Disponível em: <https://ww2.ibge.gov.br/estadosat/temas.php?sigla=al\&tema=idhm> Acesso em: 27 de out. 2017.

Instituto Brasileiro de Geografia e estatística - IBGE. Estados - Alagoas. Disponível em: <https://ww2.ibge.gov.br/estadosat/perfil.php?sigla=al>

. Alagoas em Dados e informações. Folder_AL_Numeros_NOVO_comPIB2009teste. Disponível em: $\quad$ http://dados.al.gov.br/dataset/39e0f886-9faa-4d4f-8aaf-cf4a55ae83bb/resource/521164d6-c0154d39-b21f-940c9e55e342/download/folderalnumerosnovo2011.pdf > Acesso em: 27 de out. 2017.

Disponíve

Alagoas em Dados e informações. Microsoft Word - Indicadores Basicos-finalizado 07-03 2017. 95d1fc8ca12b/resource/d2c97b5a-fe1b-4f74-b63b1a267c37e47f/download/indicadoresbasicos.pdf> Acesso em: 27 de out. 2017.

. Atlas do Desenvolvimento Humano no Brasil. Atlas Brasil, 2013 - Perfil Alagoas. Disponível em: <http://atlasbrasil.org.br/2013/pt/perfil_uf/alagoas\#idh> Acesso em: 03 de out. 2017.

Andrade, E. G. Conjuntura Regional de Alagoas, 2004. Disponível em: <http://www.conab.gov.br/OlalaCMS/uploads/arquivos/91f41390f8da7a656bb2296de93f0bba.pdf>. Acesso em: 19 jan. 2015 às $11 \mathrm{~h} 45 \mathrm{~min}$.

Plano Territorial de Desenvolvimento Rural Sustentável da Bacia Leiteira, 2011. Disponível em: <http://sit.mda.gov.br/download/ptdrs/ptdrs qua territorio036.pdf >. Acesso em: 19 jan. de 2015 às $12 \mathrm{~h} 37 \mathrm{~min}$.

JÚNIOR, Nadson A. V. Organização espacial da Bacia Leiteira no Semiárido de Alagoas. 2017. 255 f. Dissertação (Mestrado em Geografia) - Pós Graduação em Geografia, Universidade Federal de Alagoas, Maceió. 2017.

SOUZA, Raquel P. As Transformações na Cadeia Produtiva do Leite e a Viabilidade da Agricultura Familiar: O Caso do Sistema COORLAC (RS). 2007. 136 f. Dissertação (Mestrado em Desenvolvimento Rural) - Pós Graduação em Desenvolvimento Rural, Universidade Federal do Rio Grande do Sul, Porto Alegre. 2013.

SILVA, Rômulo P. Competitividade e Desenvolvimento: Evolução da Produção do Setor Lácteo das Regiões Norte e Sudeste uma análise comparativa do impacto do PRONAF na configuração do setor. 2015. 89 f. Dissertação (Mestrado em Economia Aplicada) - Pós Graduação em Economia Aplicada, Universidade Federal de Alagoas, Maceió. 2015.

SIDONIO, Luiza et al. Inovação na indústria de alimentos: importância e dinâmica no complexo agroindustrial brasileiro. Agroindústria BNDES Setorial 37, p. 333-370. Disponível em: <https://web.bndes.gov.br/bib/jspui/bitstream/1408/1512/1/A\%20mar37_08_Inova\%C3\%A7\%C3\%A30 $\% 20$ na\%20ind\%C3\%BAstria\%20de\%20alimentos_P.pdf> Acesso em: 26 de mai. 2017.

JÚNIOR, Nadson A. V. Organização Espacial Da Produção Leiteira De Alagoas: Caracterização da Cadeia de Laticínios no Semiárido. XI Encontro Nacional da ANPEGE. Diversidade da Geografia Brasileira: Escalas e Dimensões da Análise e da Ação de 9 a 12 de Outubro. P. 6199 a 6210. 2015. Disponível em: <http://www.enanpege.ggf.br/2015/anais/arquivos/22/603.pdf> Acesso em: 25 de jun. 2017.

BATALHA, Mário O. Sistemas Agroindustriais: Definições e Correntes Metodológicas. In: BATALHA, M.O. (Coord.). Gestão agroindustrial. V. 1. 3 Ed. São Paulo: Atlas, 2009.

PAES, Mariluce; AMIN, Mário M.; GOMES, Sebastião T. Agronegócio do Leite: Características da Cadeia Produtiva do Estado de Rondônia. Revista de Administração e Negócios da Amazônia, v.1, n.1,

\begin{tabular}{lllll}
\hline REVISTA ECONOMIA POLÍTICA DO DESENVOLVIMENTO & Maceió - AL & V.4 N.6. & DEZEMBRO/2017 P.48-63 Página-62
\end{tabular}


mai./ago. 2009. Disponível em: 〈http://www.periodicos.unir.br/index.php/rara/article/view/4/1 > Acesso em 25 mai. 2017.

ALMEIDA, Eraldo S. Diagnósticos da Pecuária Leiteira dos Municípios de Batalha, Major Izidoro e Craíbas, do Estado de Alagoas. 2012. 64 f. Dissertação (Mestrado em Zootecnia) - Curso de PósGraduação em Zootecnia, Universidade Federal de Alagoas, Rio Largo. 2012.

GERHARDT, Tatiana E.; Silveira, Denise T. Métodos de Pesquisa. 2009. 120 p. Coordenado pela Universidade Aberta do Brasil - UAB/UFRGS e pelo Curso de Graduação Tecnológica - Planejamento e Gestão para o Desenvolvimento Rural da SEAD/UFRGS. - Porto Alegre: Editora da UFRGS, 2009.

MATTAR, Fauze N. Pesquisa de Marketing: Edição Compacta. 2 Ed. São Paulo: Atlas, 1996.

JÚNIOR, Reynaldo R. F et al. Espaços de Combinações Tecnológicas: uma proposta metodológica para o perfil Tecnológico da Indústria de Laticínios de Alagoas. Altec 2013. Disponível em: <http://www.altec2013.org/programme_pdf/148.pdf> Acesso em 19 de mai. 2017. 